\title{
Grevisto
}

\section{NAS TRANSPARÊNCIAS DA CIDADE PRÁTICA IMAGÉTICA, PERFORMATIVA E RITUAL}

IN THE TRANSPARENCIES OF THE CITY IMAGING, PERFORMATIVE AND RITUAL PRACTICE

EN LAS TRANSPARENCIAS DE LA CIUDAD PRÁCTICA IMAGÉTICA, PERFORMATIVA Y RITUAL

\author{
Ricardo Malveira ${ }^{1}$ \\ Renata Ferreira da Silva ${ }^{2}$ \\ Renata Patrícia da Silva ${ }^{3}$ \\ Amanda Maurício Pereira Leite ${ }^{4,5}$
}

\begin{abstract}
${ }^{1}$ Doutor em Artes Cênicas no Programa de Pós-Graduação em Artes Cênicas da Universidade Federal da Bahia - PPGAC - UFBA, Mestre em Artes Cênicas no Programa de Pós-Graduação em Artes Cênicas da Universidade Federal da Bahia - PPGAC - UFBA, Pós-Graduação em ArteEducação pela Universidade Estadual de Montes Claros - Unimontes, Graduado em Educação Artística com habilitação em artes cênicas na Universidade Estadual de Montes Claros Unimontes. Professor no curso de Teatro da Universidade Federal do Tocantins. Integrante do Grupo de Pesquisa Transver. E-mail: riks.malveira@hotmail.com

2 Doutora e Mestre em Educação pelo Programa de Pós-Graduação em Educação da Universidade Federal de Santa Catarina (UFSC). Atriz. Professora no curso de Teatro da Universidade Federal do Tocantins. Coordenadora do Grupo de Pesquisa Transver. E-mail: renataferreira@mail.uft.edu.br

${ }^{3}$ Doutoranda em Artes pela Universidade Estadual Paulista. Mestre em Artes pela Universidade Federal de Minas Gerais (UFMG). Professora no curso de Teatro da Universidade Federal do Tocantins. Integrante do Grupo de Pesquisa Transver. E-mail: renatapatricia@mail.uft.edu.br

${ }^{4}$ Doutora e Mestre em Educação pelo Programa de Pós-Graduação em Educação da Universidade Federal de Santa Catarina (UFSC). Fotógrafa, pesquisadora e professora no Programa de Pós-Graduação Comunicação e Sociedade e no curso de Pedagogia da Universidade Federal do Tocantins. Integrante do Grupo de Pesquisa Transver Site: http://amandampleite.wixsite.com/amandaleite. E-mail: amandaleite@mail.uft.edu.br.

${ }_{5}^{5}$ Endereço de contato dos autores (por correio): Universidade Federal do Tocantins - UFT Campus Palmas - Avenida NS 15, 109 Norte - Plano Diretor Norte - Palmas - TO, 77001090 Brasil.
\end{abstract}




\title{
Crevisto
}

ISSN n² 2447-4266

Vol. 4, n. 2, Abril-Junho. 2018

DOI: http://dx.doi.org/10.20873/uft.2447-4266.2018v4n2p1033

\section{RESUMO}

Olhar, pensar e sentir a cidade sempre foi importante e na atualidade torna-se uma necessidade. $O$ presente estudo busca promover uma breve discussão sobre prática artística como estratégia para perceber o espaço urbano da cidade de Palmas como lugar de intervenção e pesquisa. A percepção de transparências são os resultados da performance-instalação intitulada "Na rotatória tem encruzilhada", organizada pelo grupo de pesquisa Transver.

PALAVRAS-CHAVE: Rotatória; Encruzilhada, performance-instalação.

\begin{abstract}
Looking, thinking and feeling the city has always been important and nowadays it becomes a necessity. The present study seeks to promote a brief discussion about artistic practice as a strategy to perceive the urban space of the city of Palmas as a place of intervention and research. The perception of transparencies are the results of the performance-installation entitled "At the roundabout has crossroads", organized by the research group Transver.
\end{abstract}

KEYWORDS: Rotatory; Crossroads; performance-installation.

\section{RESUMEN}

Mirar, pensar y sentir la ciudad siempre ha sido importante y en la actualidad se convierte en una necesidad. El presente estudio busca promover una breve discusión sobre práctica artística como estrategia para percibir el espacio urbano de la ciudad de Palmas como lugar de intervención e investigación. La percepción de transparencias son los resultados de la performance-instalación titulada "En la rotatoria tiene encrucijada", organizada por el grupo de investigación Transver.

PALABRAS CLAVE: Rotatoria; Encruzilhada, rendimiento-instalación.

Recebido em: 12.02.2017. Aceito em: 16.03.2018. Publicado em: 01.04.2018. 


\section{Crevisto}

ISSN n² 2447-4266

Vol. 4, n. 2, Abril-Junho. 2018

DOI: http://dx.doi.org/10.20873/uft.2447-4266.2018v4n2p1033

Os espaços que compõem a cidade sempre convidaram artistaseducadores e educadores-artistas a ações que despertam outras percepções, bem como levantam discussões que promovem mudanças de comportamento frente o viver e o ocupar a cidade. Ao pensarmos sobre o nosso lugar no espaço urbano, muitas vezes, questionamos como podemos vivenciar vários lugares ao traçar novos trajetos. Neste vasto campo de possibilidades, o que foge do nosso olhar chamaremos aqui de transparências da cidade.

$\mathrm{Na}$ direção desta inquietação o presente estudo tem como objetivo apresentar a performance-instalação intitulada "Na rotatória tem encruzilhada", proposta pelo grupo de pesquisa Transver ${ }^{6}$, com intuito de promover a discussão e a prática artística como estratégia para perceber a cidade de Palmas. Nos encontros do Transver, ao pensarmos a cidade de Palmas, notamos que somos moradores vindos de outras regiões do país, ou seja, estrangeiros. Neste sentido, nossas sensações relacionadas ao modo como percebemos a cidade é de alguma forma diferente. Concordamos que a cidade exibe imensas quadras, grandes avenidas, casas com grandes muros, praças, lago artificial de grande dimensão e ainda, muito espaço vazio.

Uma das características urbana que marca consideravelmente nossas discussões é a presença maciça de rotatórias ${ }^{7}$. A cada 500 metros temos uma

\footnotetext{
${ }^{6}$ Transver - Grupo de pesquisa que tem como objetivo estudar as fronteiras entre Educação, Comunicação e Arte. É composto por professores e acadêmicos do curso de Licenciatura em Teatro e Pedagogia da Universidade Federal do Tocantins, UFT, Palmas/TO, além de colaboradores da comunidade acadêmica e interessados. http://www.transver.com.br/index.php/pt/

${ }^{7}$ Rotatória ou Rótula: "Praça circular onde desembocam várias vias e o trânsito se move em sentido anti-horário. A função da rotatória é eliminar, numa interseção em nível de duas ou mais vias, todas cruzadas transformando-as em interseções divergentes e convergentes (FERRARI, 2004, pg. 328)
} 


\section{Crevisto}

ISSN n² 2447-4266

Vol. 4, n. 2, Abril-Junho. 2018

DOI: http://dx.doi.org/10.20873/uft.2447-4266.2018v4n2p1033

rotatória chegando a aproximadamente mais de 250 rotatórias espalhadas pela cidade. Depois muitas leituras, discussões, exercícios de deriva e errância no grupo de pesquisa, organizamos uma experiência com base no conceito de ritual-processo ${ }^{8}$, formatado em performance-instalação. Nesta proposta não aprofundaremos o lugar antropológico da encruzilhada deixando-o para um estudo específico da proposta de intervenção. Mas aqui, apresentamos como aconteceu a performance resultante de nossas pesquisas.

\section{Ritual-Processo: na rotatória tem encruzilhada}

Velas dentro de sacos de papel com areia construíam caminhos no meio da rotatória entre a Avenida NS-01 com Avenida LO-02, no dia 10 de março de 2017, a partir das 18h na cidade de Palmas/TO ${ }^{9}$. Um espaço circular. Interseção de caminhos. Árvores dispostas nas laterais do círculo e grama compunham a rotatória que tinha um poste de luz no centro.

Um grupo de pessoas em sua maioria vestidas de branco, caminham no espaço circular da rótula que anteriormente era apenas frequentado por mendigos, pessoas apressadas que se arriscavam cortar caminho, vez por outra travestis e formigas que produziam vários diferentes trajetos em todo o espaço.

\footnotetext{
${ }^{8}$ Ritual-processo foi uma terminologia para a experimentação-criação de caráter operatório com base no jogo, no lúdico, no ritual e a performatividade inspirada no pensamento de Richard Schechner, e que está na base das práticas das Teatralituras (MALVEIRA, 2015).

9 "Palmas, a mais nova capital brasileira, criada em 1989 para ser a sede administrativa do recém criado Estado do Tocantins, está localizada na porção central do estado, praticamente equidistante de duas das suas principais cidades: Porto Nacional (cidade histórica localizada às margens do Rio Tocantins) e Paraíso do Tocantins (localizada às margens da BR-153, popularmente conhecida como Belém-Brasília) (ORSI; ASSIS in Reis, 2015, p. 88).
} 


\section{Oevisto}

ISSN n² 2447-4266

Vol. 4, n. 2, Abril-Junho. 2018

DOI: http://dx.doi.org/10.20873/uft.2447-4266.2018v4n2p1033

As luminárias improvisadas reconstruíam a continuidade das vias que foram interrompidas pela rotatória. Nesta intervenção várias direções foram criadas por fios de barbantes esticados entre as extremidades do círculo. Estes fios, amarrados na parte superior do poste central criaram uma teia que se sobrepunha ao cruzamento das velas dispostas no chão. O som de um pandeiro quadrado e um violão embalavam os participantes que amarravam fitinhas brancas de seda nos longos fios de barbante. Cada fita amarrada um pedido, um sonho, um desejo... Instalou-se ali uma prática imagética, performativa e ritual.

O coletivo de pesquisadores e convidados criaram outra realidade naquele espaço urbano. Movimento que chamou a atenção das pessoas que passavam nas vias ou circundam a rotatória. Transeuntes e motoristas observavam curiosos o que acontecia. Algumas pessoas se arriscaram mais e entraram na rotatória para perguntar o que está acontecendo. Alguns motoristas deram várias voltas na tentativa de entender que movimento e os caminhos que as luminárias sugeriam. Outros gritaram "isto é macumba!". As travestis que trabalhavam próximos daquele espaço perguntam: "Quanto tempo isso vai durar?". A preocupação era de que a ação interferisse nos programas daquela noite de trabalho. Patrulhas de policiais também passaram muitas vezes verificando se a ação estava tumultuando a ordem pública.

A performance-instalação "Na rotatória tem encruzilhada", elaborada e produzida pelo grupo de pesquisa Transver, resultou de um dos ciclos de estudo que teve como tema a cidade. A ação estreou no evento "Escala 1. 1: Ações humanas em espaços monumentais" organizado pelo Sesc Tocantins, edição 2017. Esta ação funcionou como uma tela transparente de possiblidades sutis sobre o uso e a ocupação do espaço, espaço modificado, espaço coletivo. 


\section{Crevisto}

ISSN n² 2447-4266

Vol. 4, n. 2, Abril-Junho. 2018

DOI: http://dx.doi.org/10.20873/uft.2447-4266.2018v4n2p1033

Como inspiração para pensar, viver e sonhar a cidade estudamos as "cidades ocultas" de Ítalo Calvino, no livro "As cidades invisíveis".

Talvez toda a questão seja saber quais palavras pronunciadas, quais gestos exercidos, e em que ordem e ritmo, ou então basta o olhar a resposta, o aceno de alguém, basta que alguém faça alguma coisa pelo simples prazer de fazê-la, e para que o seu prazer se torne um prazer para os outros, naquele momento todos os espaços se alteram, as alturas, as distâncias, a cidade se transforma, torna-se cristalina, transparente como uma libélula (CALVINO, 1990, p. 67)

O espaço da rotatória foi resignificado, ocupado na configuração da encruzilhada-rotatória. Simbolicamente, o plano do caminho traz para alguns a força do imaginário afro-brasileiro das encruzilhadas, para outros, um desenho iluminado em um espaço incomum. O plano das fitas faz referência ao universo dos pedidos em nome da fé cristã. O movimento entre os participantes, motoristas e os curiosos ao redor da rotatória, tencionava o espaço cotidiano de pessoas que moram nas ruas, que trabalham na rua ou que simplesmente atravessa o espaço no deslocamento habitual. Todos tiverem que se adaptar à intervenção. Perto das 22:00 horas encerramos a performance com o apagar das velas. Os materiais foram recolhidos pelo grupo de pesquisa. A rotatória voltou a sua função primária. As pessoas se dispersaram, mas o pensamento que segue latente até agora é sobre as muitas formas que temos e podemos ocupar os espaços.

A proposta-ação entendida aqui também como um ritual-processo, cumpriu sua função de promover aos participantes o exercício de performar e ritualizar outra relação com a cidade. O público teve uma vivência performativa e ritualística, experimentou também o exercício de olhar o espaço da rotatóriaencruzilhada por outras perspectivas. Este espaço, quase invisível, despertou muitos questionamentos, afinal: que caminhos e teias produziram no 


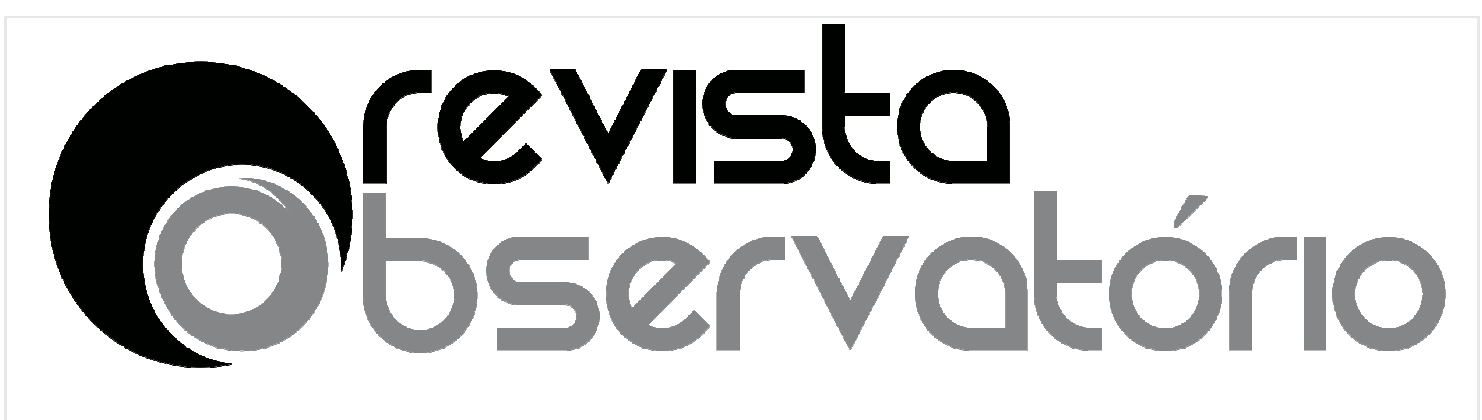

ISSN n² 2447-4266

Vol. 4, n. 2, Abril-Junho. 2018

DOI: http://dx.doi.org/10.20873/uft.2447-4266.2018v4n2p1033

imaginário coletivo? Seria aquela proposta um protesto? Uma ação particular de um grupo de amigos? Uma prática religiosa (considerando que em nosso país deveria existir a liberdade de práticas religiosas), ou seria uma prática artística? Sim, foi tudo isto no formato de uma prática imagética, performativa e ritual. As percepções ali dilatadas revelavam camadas até então transparentes no espaço. Na rotatória teve uma encruzilhada que instalou sua presença na forma, no gesto, no ritual. Uma ocupação transformação.

\section{Referências}

CALVINO, Ítalo. As cidades invisíveis. São Paulo: Companhia das Letras, 1990. FERRARI, Celson. Dicionário de Urbanismo. $1^{\text {a }}$ ed. São Paulo. Editora Disal, 2004.

MALVEIRA, Ricardo Ribeiro. Teatralituras: escrituras (en) cena do Catopê (Tese), Programa de Pós-Graduação em Artes Cênicas, Universidade Federal da Bahia, Salvador, 2015. 


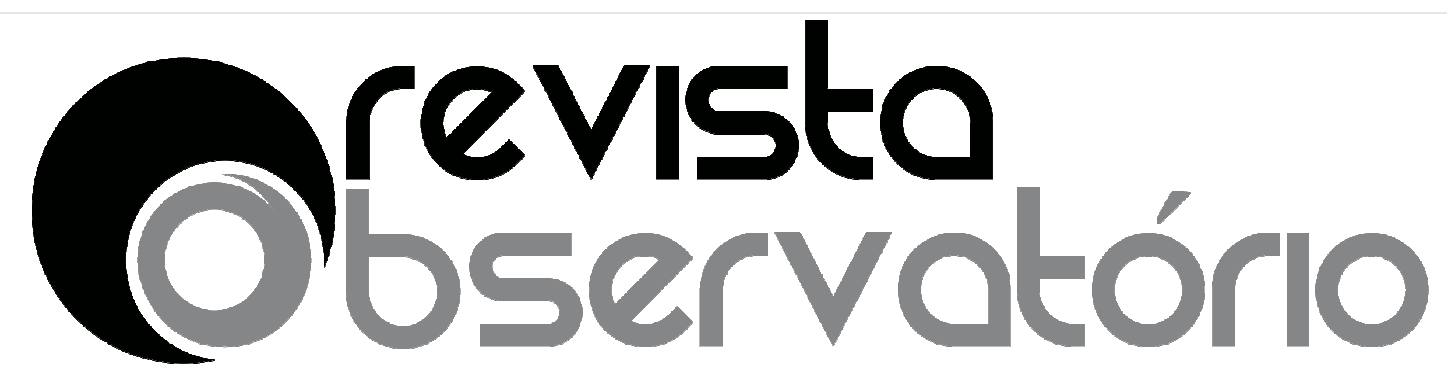

ISSN n² 2447-4266

Vol. 4, n. 2, Abril-Junho. 2018

DOI: http://dx.doi.org/10.20873/uft.2447-4266.2018v4n2p1033

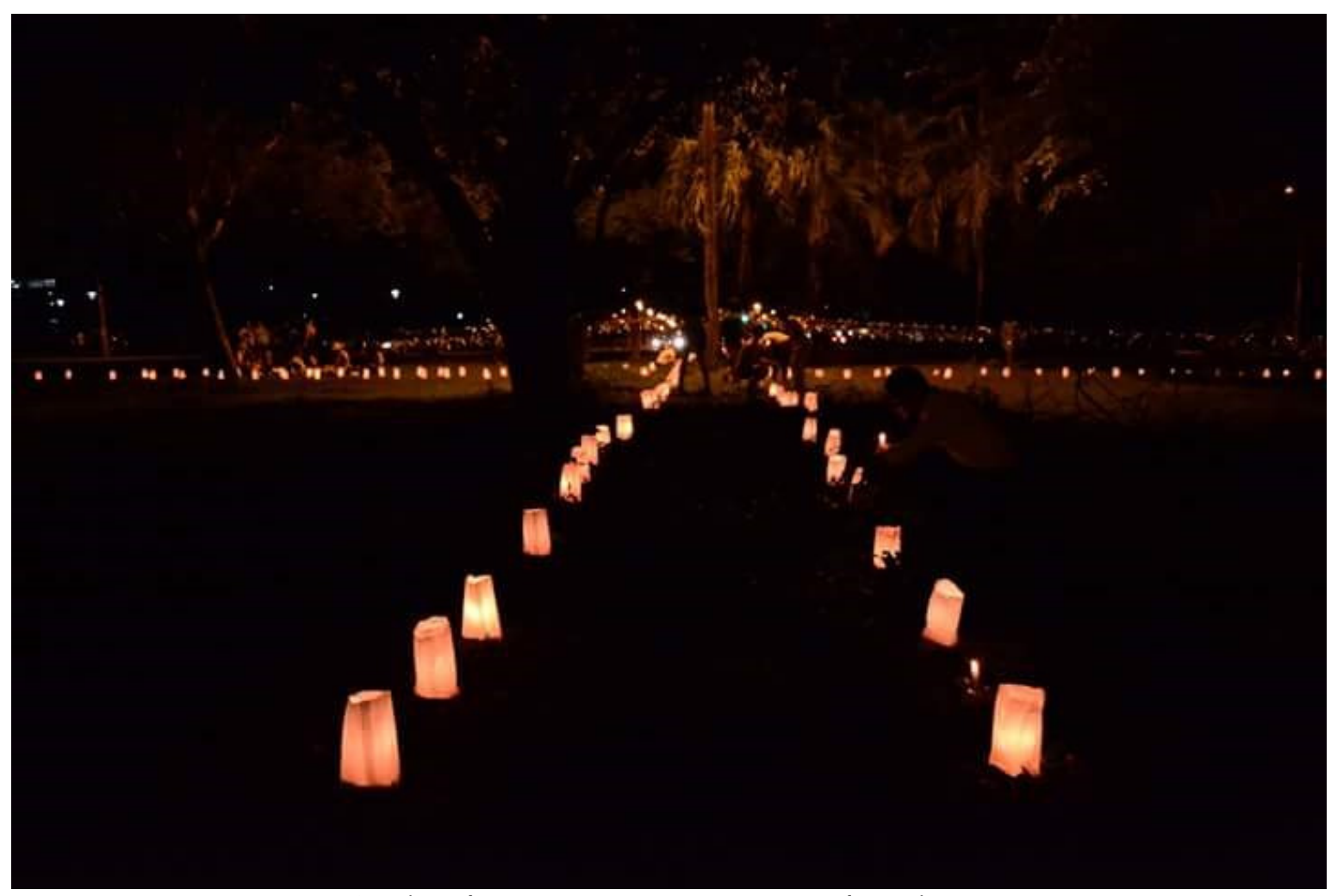

01. Ritual-processo. Foto Amanda Leite 


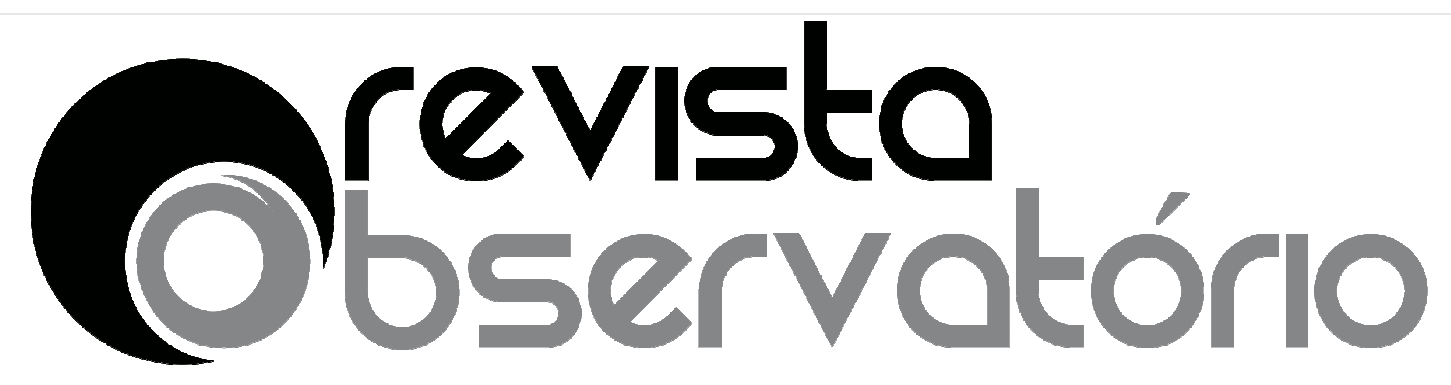

ISSN n² 2447-4266

Vol. 4, n. 2, Abril-Junho. 2018

DOI: http://dx.doi.org/10.20873/uft.2447-4266.2018v4n2p1033

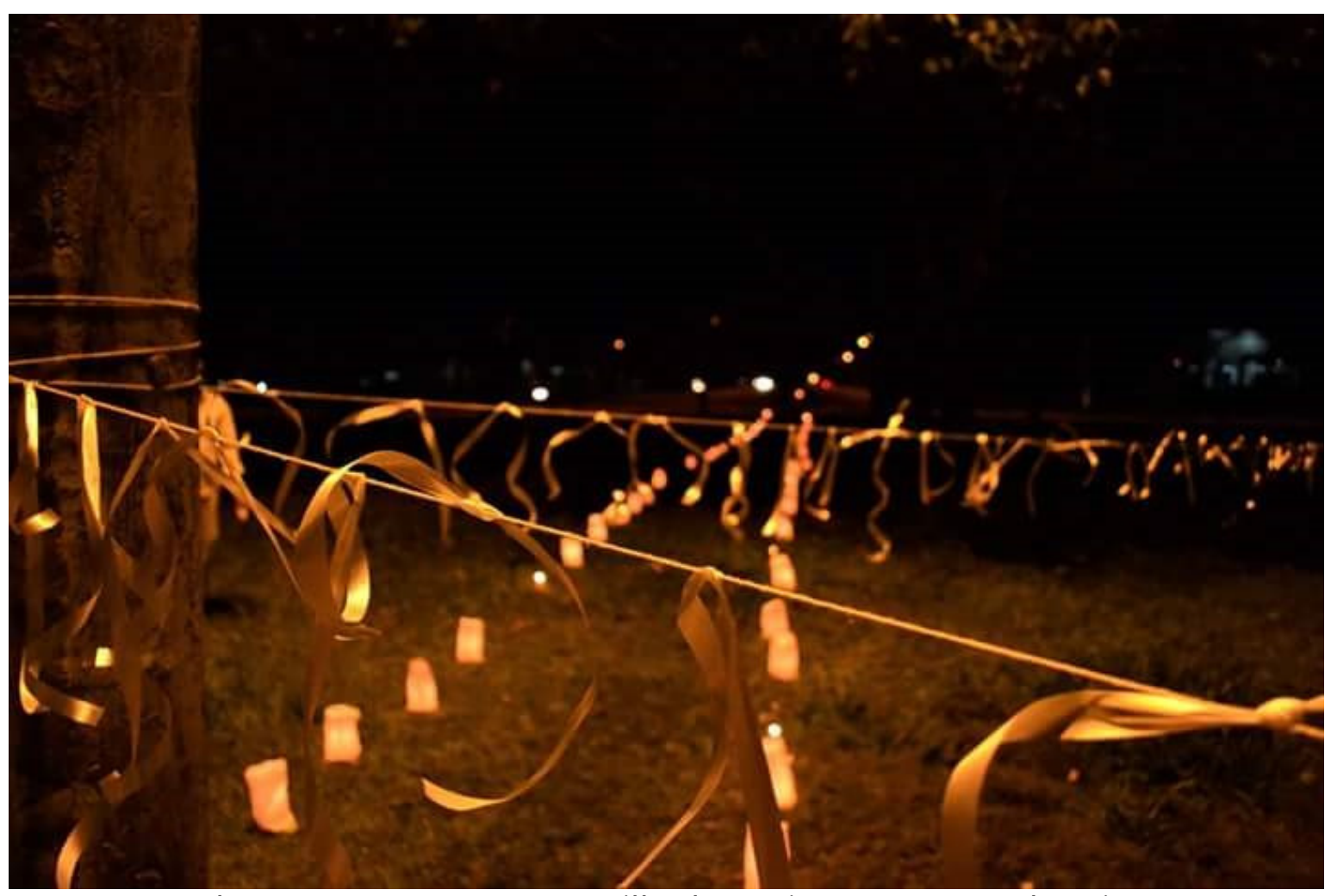

02. Planos postos entre encruzilhada e teia. Foto Amanda Leite 


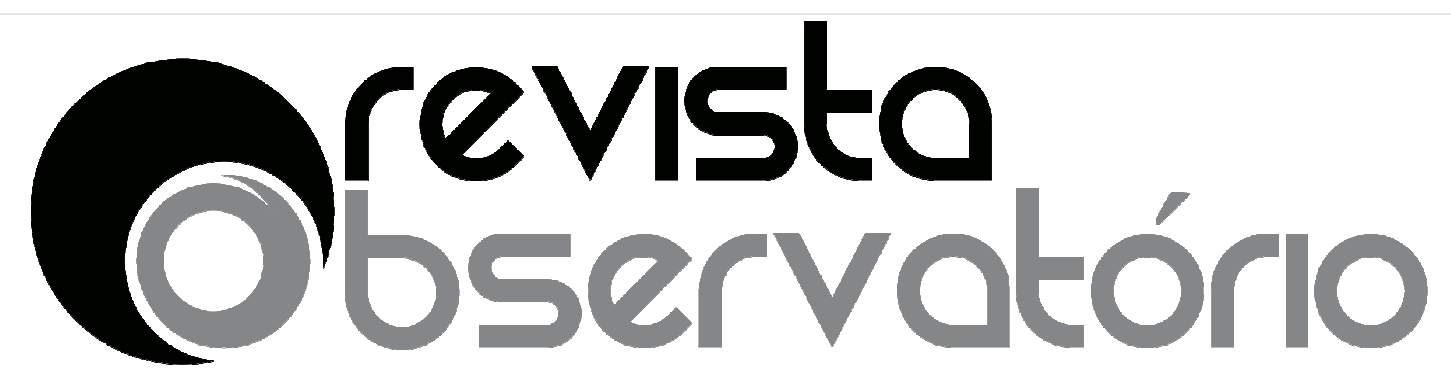

ISSN n² 2447-4266

Vol. 4, n. 2, Abril-Junho. 2018

DOI: http://dx.doi.org/10.20873/uft.2447-4266.2018v4n2p1033

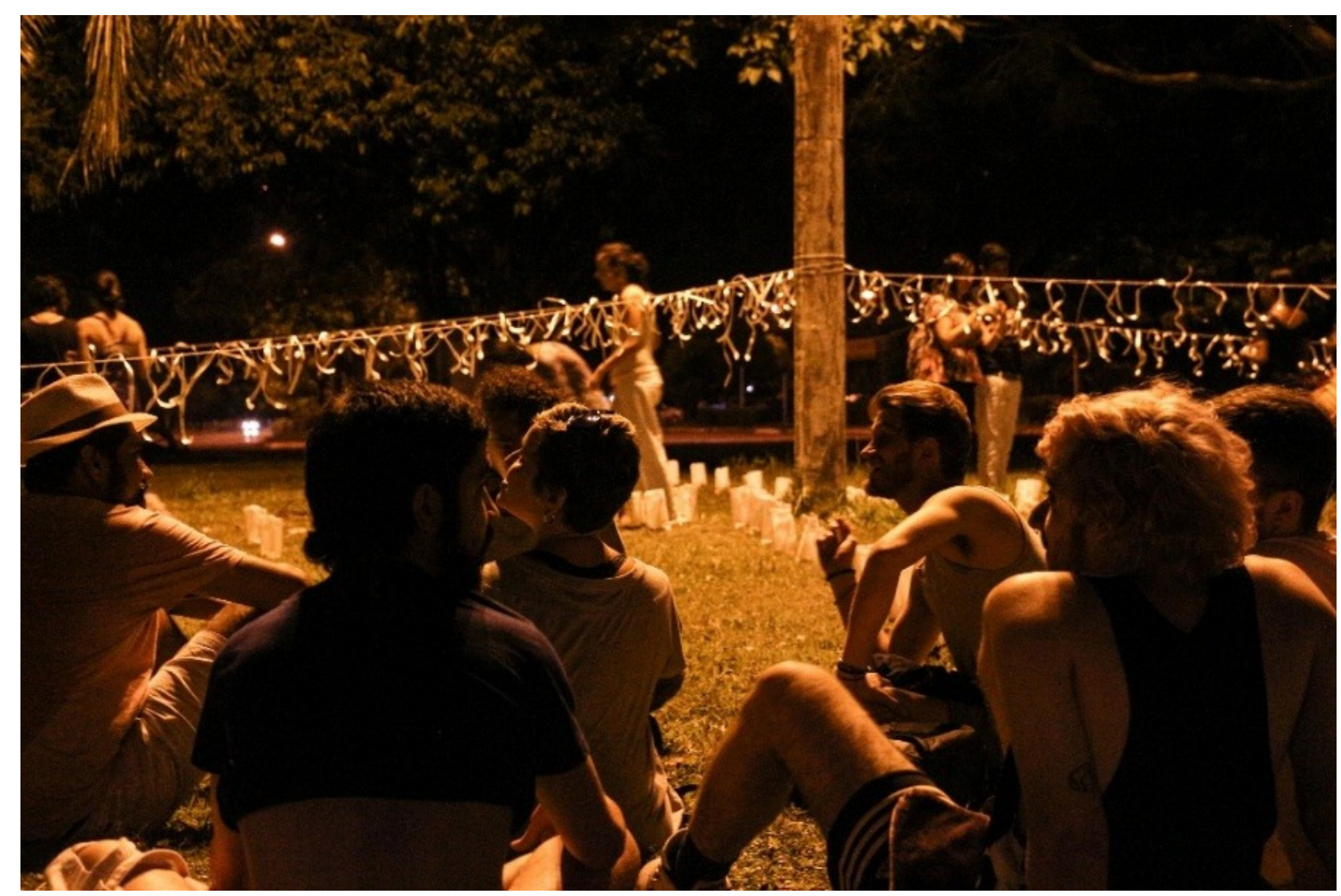

03. Participantes e observadores na encruzilhada da rotatória. Foto Amanda Leite 


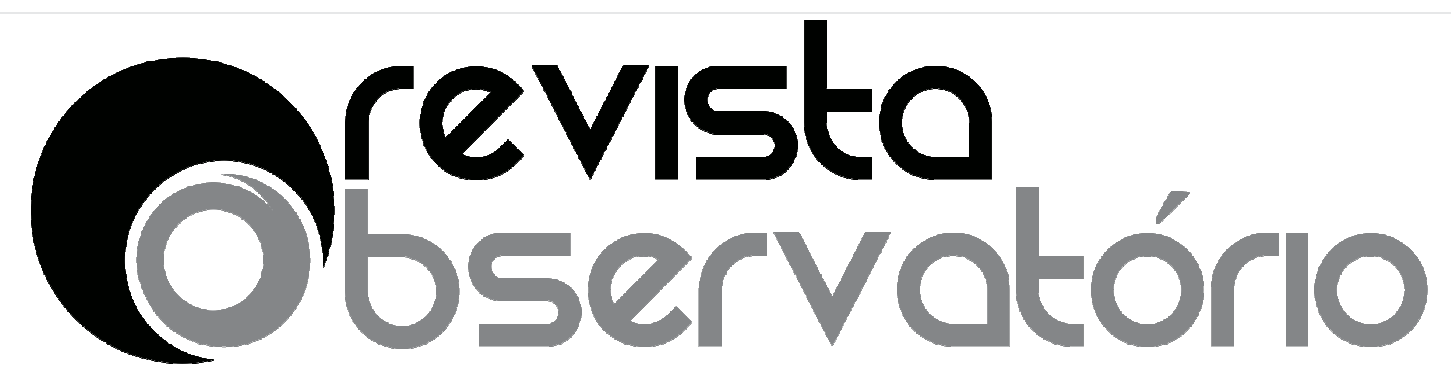

ISSN n² 2447-4266

Vol. 4, n. 2, Abril-Junho. 2018

DOI: http://dx.doi.org/10.20873/uft.2447-4266.2018v4n2p1033

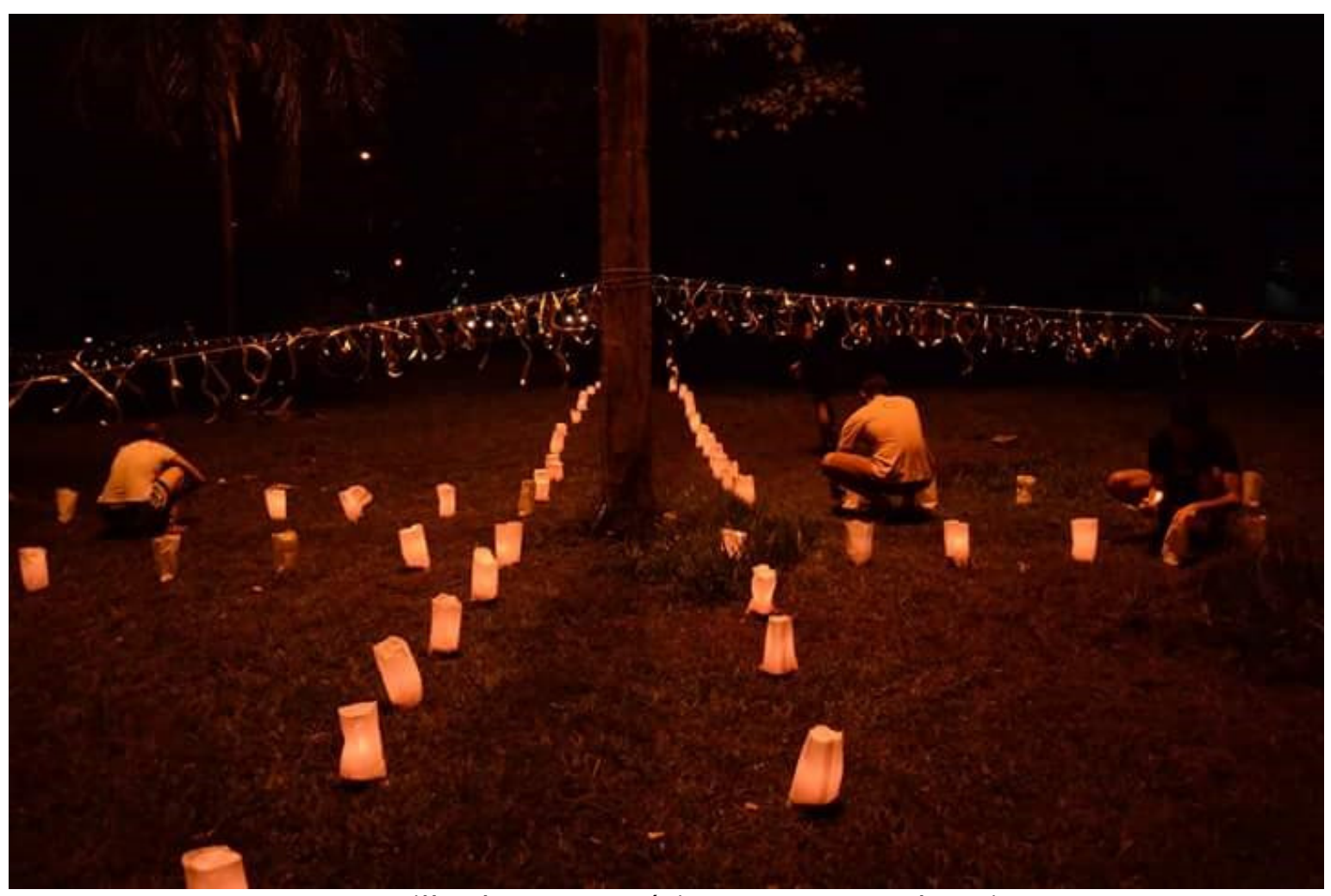

04. Encruzilhada na rotatória. Foto Amanda Leite 


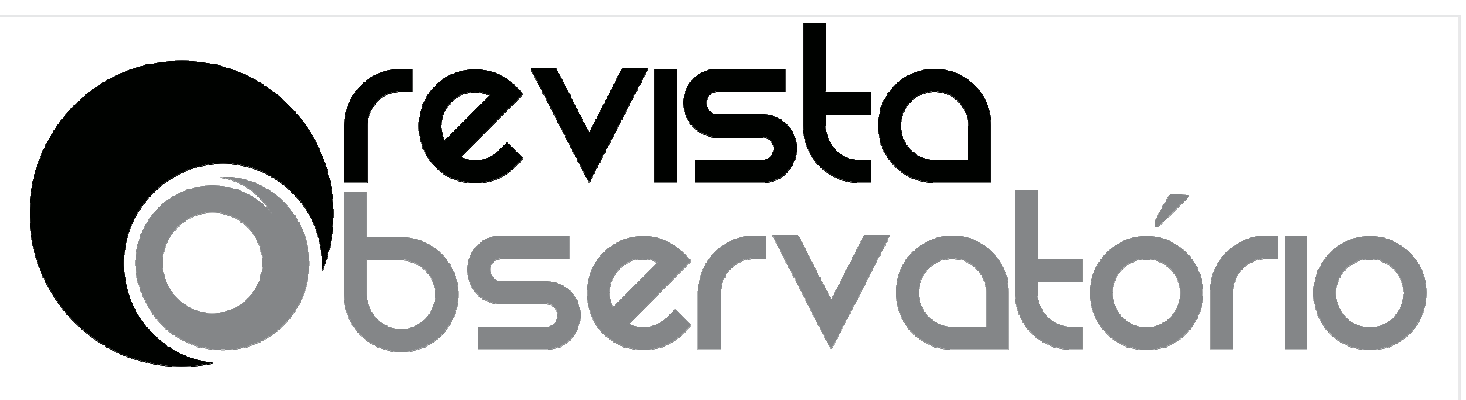

ISSN n² 2447-4266

Vol. 4, n. 2, Abril-Junho. 2018

DOI: http://dx.doi.org/10.20873/uft.2447-4266.2018v4n2p1033

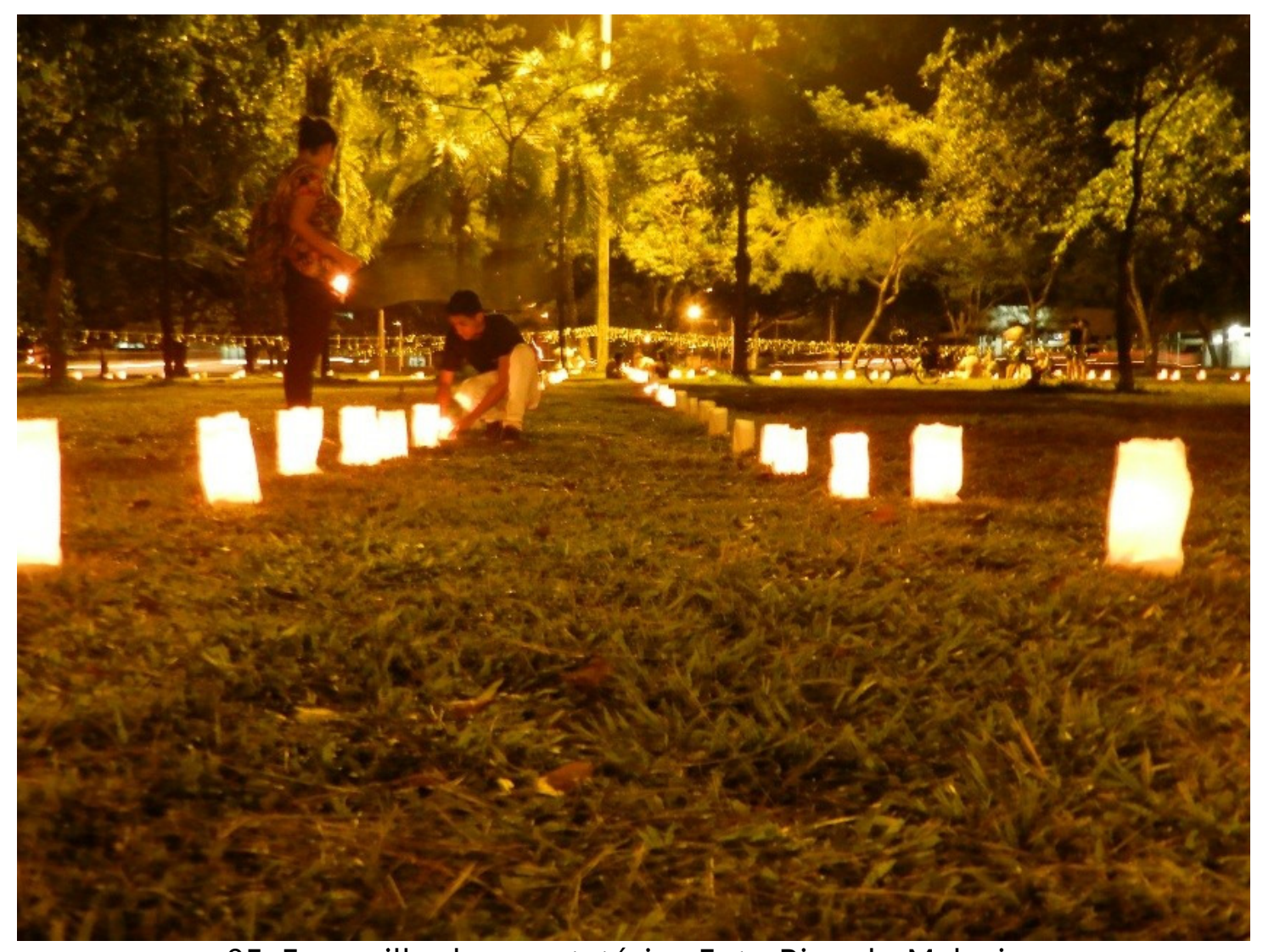

05. Encruzilhada na rotatória. Foto Ricardo Malveira 


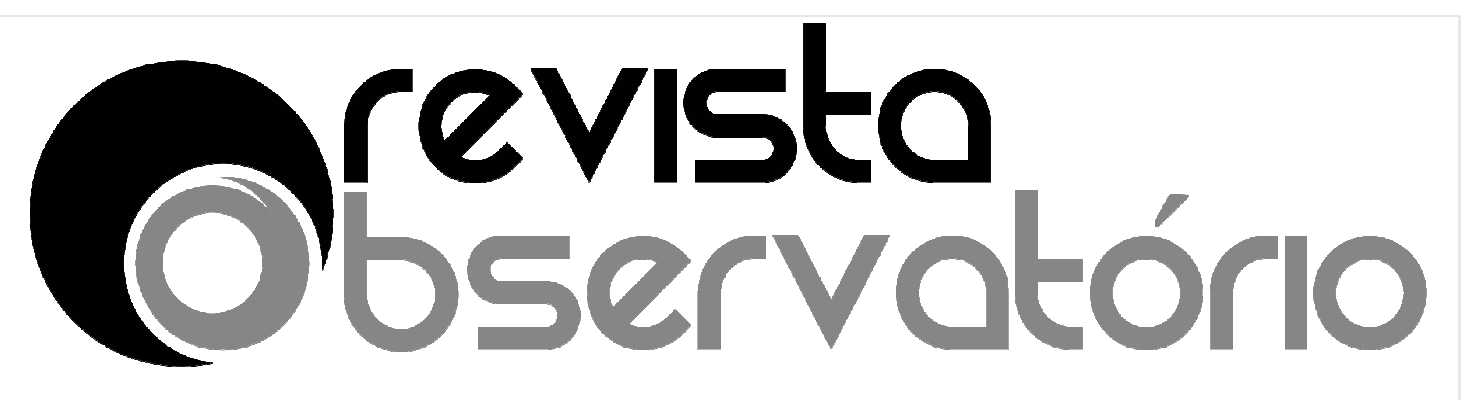

ISSN n² 2447-4266

Vol. 4, n. 2, Abril-Junho. 2018

DOI: http://dx.doi.org/10.20873/uft.2447-4266.2018v4n2p1033

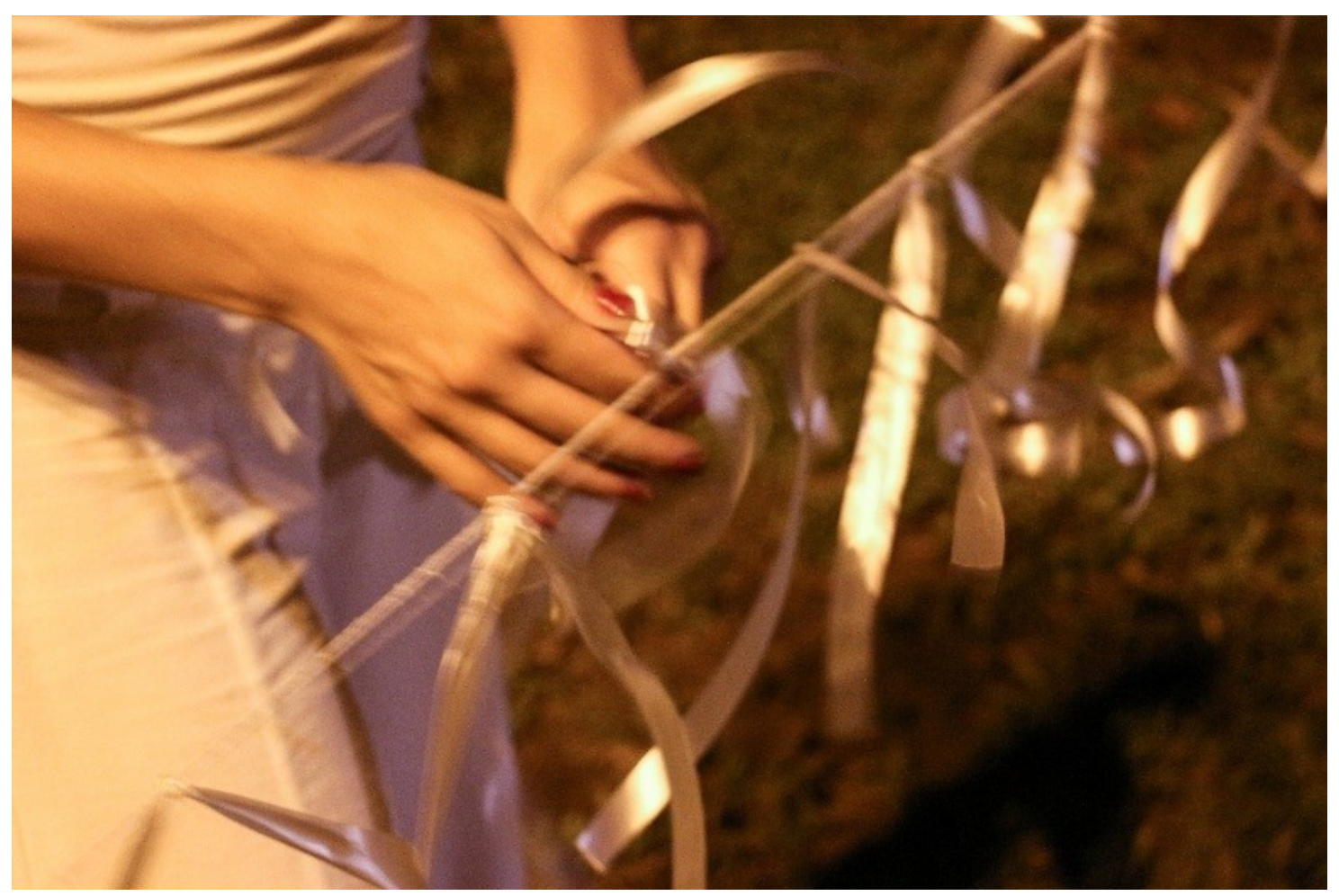

06. Fios na encruzilhada. Foto Ronan Gonçalves 